\title{
Síntese e caracterização do espinélio $\mathrm{MgAl}_{2} \mathrm{O}_{4}$
}

\author{
Buffon, E. ${ }^{1}$; Profeti, D. ${ }^{1}$; Profeti, L. P. R. ${ }^{1}$ \\ 1 Departamento de Química e Física, Centro de Ciências Agrárias, Universidade Federal do Espírito Santo, Alegre, \\ ES, Brasil
}

\begin{abstract}
Resumo
$\mathrm{O} \mathrm{MgAl}_{2} \mathrm{O}_{4}$ é um material policristalino bastante utilizado devido à uma combinação de propriedades interessantes, tais como boa resistência mecânica e alta estabilidade na presença de soluções ácidas ou básicas. Devido ao caráter básico de sua superfície, o $\mathrm{MgAl}_{2} \mathrm{O}_{4}$ pode ser utilizado como catalisador heterogêneo para a reação de produção de biodiesel. Dentro deste contexto, neste trabalho foi preparado o aluminato de magnésio pelo método de impregnação úmida de $\gamma-\mathrm{Al}_{2} \mathrm{O}_{3}$ com solução aquosa de $\mathrm{Mg}\left(\mathrm{NO}_{3}\right)_{2} .6 \mathrm{H}_{2} \mathrm{O}$ e calcinado a $900^{\circ} \mathrm{C}$ sob fluxo de ar por 5 horas. O material obtido foi caracterizado pelas técnicas de Difração de Raios-X (DRX), Espectroscopias nas regiões do infravermelho (FTIR) e UV-vis. Os resultados mostraram que o método de preparação proporcionou a formação da fase espinélio de estrutura cúbica. Contudo, o sólido formado contém fases referentes ao $\mathrm{MgO}$ e $\gamma-\mathrm{Al}_{2} \mathrm{O}_{3}$ não convertidos.
\end{abstract}

Keywords (Palavras chaves): $\mathrm{MgAl}_{2} \mathrm{O}_{4}$, Síntese, Caracterização

\section{Introdução}

O crescente avanço do desenvolvimento tecnológico estimula a busca por materiais que possuam propriedades que permitam aplicações em diversas áreas. Neste contexto, o aluminato de magnésio $\left(\mathrm{MgAl}_{2} \mathrm{O}_{4}\right)$ é um material que possui boa combinação de propriedades, tais como alta temperatura de fusão, boa resistência mecânica, baixa constante dielétrica e alta estabilidade na presença de soluções ácidas ou básicas. Tais características fazem com que o $\mathrm{MgAl}_{2} \mathrm{O}_{4}$ seja adequado para diversas aplicações nas indústrias química, cerâmica, metalúrgica e elétrica [1].

Considerando aplicações em processos químicos industriais, o $\mathrm{MgAl}_{2} \mathrm{O}_{4}$ possui propriedades que o torna um potencial catalisador para reações de transesterificação de óleos vegetais com álcoois de cadeia curta, visando à produção de biodiesel. Devido ao caráter básico de sua superfície, o $\mathrm{MgAl}_{2} \mathrm{O}_{4}$ pode ser utilizado como catalisador heterogêneo da reação e reduzir custos associados ao processo convencional de produção de biodiesel via catálise homogênea, facilitando a separação e purificação do combustível [2].

Dentro deste contexto, o objetivo deste trabalho foi preparar o aluminato de magnésio pelo método de impregnação e caracterizar quanto à sua estrutura visando a posterior aplicação deste material como catalisador de reações de transesterificação.

\section{Metodologia}

O aluminato de magnésio foi preparado pelo método de impregnação úmida de $\gamma-\mathrm{Al}_{2} \mathrm{O}_{3}$ com solução aquosa de $\mathrm{Mg}\left(\mathrm{NO}_{3}\right)_{2} .6 \mathrm{H}_{2} \mathrm{O}$ (razão molar $\mathrm{Mg}: \mathrm{Al}=1: 2$ ), seguido por evaporação do solvente sob pressão reduzida em um evaporador rotativo [3]. O material foi seco em estufa a $90{ }^{\circ} \mathrm{C}$ por 12 horas e posteriormente calcinado a 900 ${ }^{\circ} \mathrm{C}$ sob fluxo de ar por 5 horas. Antes da preparação, a $\gamma-\mathrm{Al}_{2} \mathrm{O}_{3}$ foi peneirada e classificada com granulometria entre 60 e 80 mesh. Além disso, a $\gamma-\mathrm{Al}_{2} \mathrm{O}_{3}$ foi tratada termicamente a $550{ }^{\circ} \mathrm{C}$ por 3 horas sob fluxo de ar para remover contaminantes adsorvidos.

O material obtido foi caracterizado por Difração de Raios-X (DRX) usando a radiação $\mathrm{K} \alpha$ do $\mathrm{Cu}(1,5406$ $A^{\circ}$ ), Espectroscopias nas regiões do infravermelho (FTIR) e UV-vis.

\section{Resultados e Discussão}

A estrutura cristalina do $\mathrm{MgAl}_{2} \mathrm{O}_{4}$ foi investigada por DRX em um intervalo de $2 \theta$ variando entre 10 e $70^{\circ}$. A Figura 1 mostra o difratograma de raios-X obtido para o material calcinado a $900^{\circ} \mathrm{C}$ onde se observam os picos de difração em $2 \theta=19,31,36,45,60$ e $65^{\circ}$, os quais correspondem, respectivamente, aos planos (111), (220), (311), (422), (511) e (440) da fase espinélio de estrutura cúbica do aluminato de magnésio (JCPDS 741132).

Picos referentes às fases cristalinas da $\gamma-\mathrm{Al}_{2} \mathrm{O}_{3}$ e $\mathrm{MgO}$ também foram encontrados indicando que o método de preparação não proporcionou somente a formação da estrutura $\mathrm{MgAl}_{2} \mathrm{O}_{4}$. Tal fato já era esperado uma vez 
que a transformação de $\gamma-\mathrm{Al}_{2} \mathrm{O}_{3}$ no espinélio $\mathrm{MgAl}_{2} \mathrm{O}_{4}$ requer a difusão do magnésio no interior da estrutura cristalina da $\gamma-\mathrm{Al}_{2} \mathrm{O}_{3}$ e rearranjo dos íons alumínio e magnésio entre os sítios intersticiais octaédricos e tetraédricos. Contudo, na prática, os espinélios dificilmente existem com $100 \%$ de ordenação em sua estrutura, pois existe uma probabilidade finita, baseada em equilíbrio termodinâmico, do íon magnésio ocupar um sítio octaédrico normalmente ocupado pelo íon alumínio [4].

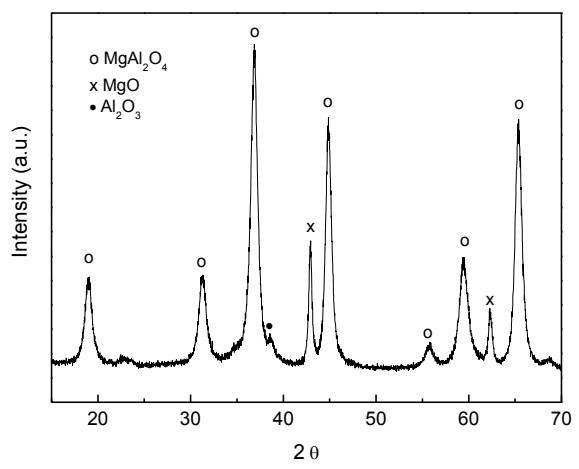

Figura 1: Difratograma de raios- $\mathrm{X}$ do aluminato de magnésio.

O espectro obtido na região do infravermelho entre 4000 e $400 \mathrm{~cm}^{-1}$ está mostrado na Figura 2. A banda de absorção entre $3200-3700 \mathrm{~cm}^{-1}$ corresponde ao estiramento $\mathrm{O}-\mathrm{H}$ da molécula de $\mathrm{H}_{2} \mathrm{O}$ e o pico em torno de $2370 \mathrm{~cm}^{-1}$ é atribuído ao $\mathrm{CO}_{2}$ que pode estar adsorvido nos sítios básicos superficiais do $\mathrm{MgAl}_{2} \mathrm{O}_{4}$. As bandas de absorção presentes entre 1000 e 400 $\mathrm{cm}^{-1}$ são atribuídas às ligações Metal-Oxigênio (M-O-M) [3]. Os picos localizados nas frequências entre 550 e $700 \mathrm{~cm}^{-1}$ são atribuídos aos grupos [AIO $]$ e à vibração de estiramento da ligação $\mathrm{Mg}-\mathrm{O}$, indicando a presença do espinélio $\mathrm{MgAl}_{2} \mathrm{O}_{4}$ [5].

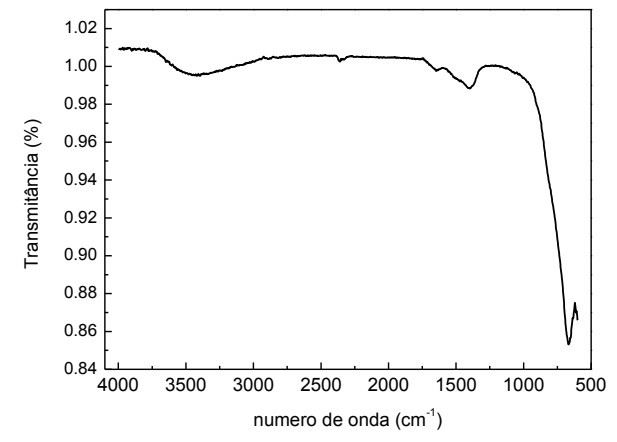

Figura 2: Espectro de FTIR do aluminato de magnésio.

O espectro obtido na região do UV-vis. está mostrado na Figura 3, onde observa-se banda de absorção na região próxima à região da luz visível, a qual pode ser atribuída à transição de carga $\mathrm{O}^{2-} \rightarrow \mathrm{Al}^{3+}$ devido à excitação dos elétrons da banda de valência do oxigênio (2p) para a banda de condução do alumínio (3d), confirmando a presença do composto formado [6].

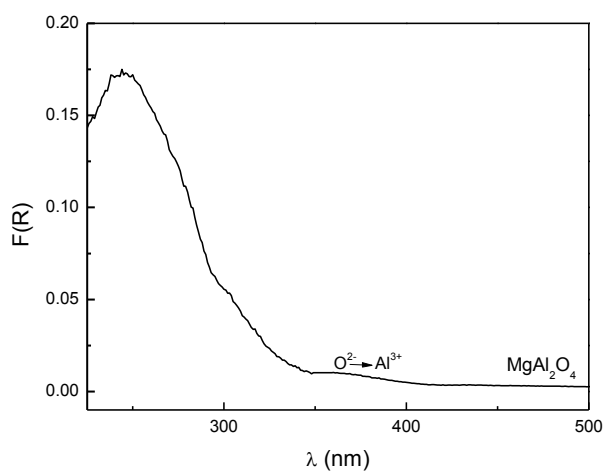

Figura 3: Espectro de UV-vis. do aluminato de magnésio.

\section{Conclusão}

Neste trabalho foi sintetizado $0 \quad \mathrm{MgAl}_{2} \mathrm{O}_{4}$ por impregnação úmida da $\gamma-\mathrm{Al}_{2} \mathrm{O}_{3}$ com nitrato de magnésio. O método de preparação proporcionou a formação da fase espinélio de estrutura cúbica confirmada pelo difratograma de raios- $X$. Contudo, 0 sólido formado contém fases referentes ao $\mathrm{MgO}$ e $\gamma$ $\mathrm{Al}_{2} \mathrm{O}_{3}$ não convertidos.

\section{Agradecimentos}

Os autores agradecem a Fundação de Amparo a Pesquisa do Espírito Santo (FAPES) pelo auxílio concedido e ao Programa Institucional de Iniciação Tecnológica da Universidade Federal do Espírito Santo.

\section{Referências}

[1] NUERNBERG, G. D.B.; FOLETTO, E. L.; PROBST, L. F.D.; CAMPOS, C. E.M.; CARREÑO, N. L.V.; MOREIRA, M. A. Chem. Eng. J., v.193-194, p. 211$214,2012$.

[2] SUN, J.; YANG, J.; LI, S.; XU, X. Catal. Commun., v. 52, p. $1-4,2014$.

[3] LIN, K.-S.; CHOWDHURY, S.; SHEN, C.-C.; YEH, C.-T. Catal. Today, v.136, p. 281-290, 2008.

[4] SHARMA, Y.; SHARMA, N.; SUBBA RAO, G.V.; CHOWDARI, B.V.R. Solid State Ionics, v.179, p.587$597,2008$.

[5] CHANDRADASS, J.; KIM,K. H. J. Ceram. Process. Res., v. 11, p. 96-99, 2010.

[6] NASSAR, M.Y.; AHMED, I. S.; SAMIR, I. Spectrochim. Acta, in press. 